\title{
Priority setting for reproductive health at the district level in the context of health sector reforms in Ghana
}

\author{
Harriet Birungi \\ Population Council \\ Philomena Nyarko \\ Population Council \\ Ian Askew \\ Population Council \\ Ayorinde Ajayi \\ Population Council \\ Gifty Addico
}

See next page for additional authors

Follow this and additional works at: https://knowledgecommons.popcouncil.org/departments_sbsr-rh

Part of the Demography, Population, and Ecology Commons, Health Policy Commons, International Public Health Commons, and the Women's Health Commons

How does access to this work benefit you? Let us know!

\section{Recommended Citation}

Birungi, Harriet, Philomena Nyarko, lan Askew, Ayorinde Ajayi, Gifty Addico, Edward Addai, and Caroline Jehu-Appiah. 2006. "Priority setting for reproductive health at the district level in the context of health sector reforms in Ghana," FRONTIERS Final Report. Washington, DC: Population Council. 


\section{Authors}

Harriet Birungi, Philomena Nyarko, Ian Askew, Ayorinde Ajayi, Gifty Addico, Edward Addai, and Caroline Jehu-Appiah 


\section{Priority Setting for Reproductive Health at the District Level in the context of Health Sector Reforms in Ghana}

April 2006

Population Council

Harriet Birungi, Philomena Nyarko

Ian Askew, Ayo Ajayi

UNFPA/Ghana

Gifty Addico
Ministry of Health, Ghana

Edward Addai

Ghana Health Service

Caroline Jehu-Appiah

This study was funded by UNFPA under Contract Agreement Number UNFPA/SSA/05/30 with funding from the European Commission (EC) under the terms of the UNFPA/EC/GOG Project, the United States Agency for International Development (USAID) under the terms of the FRONTIERS Cooperative Agreement Number HRN-A-00-98-00012-00 and the Population Council under In-house Project 5800 53086. The opinions expressed herein are those of the authors and do not necessarily reflect the views of the sponsors. 


\section{Table of Contents}

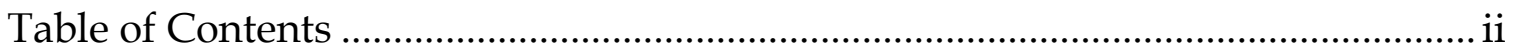

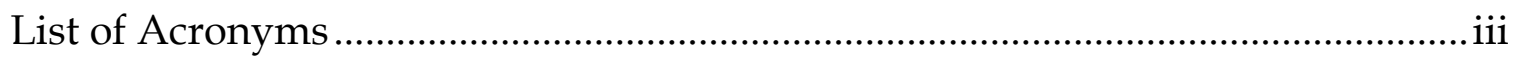

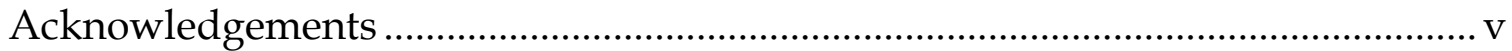

Executive Summary .............................................................................................. vi

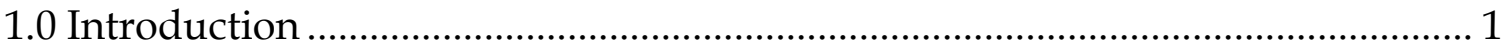

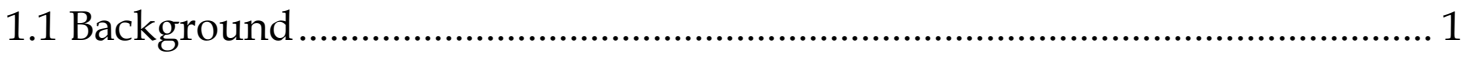

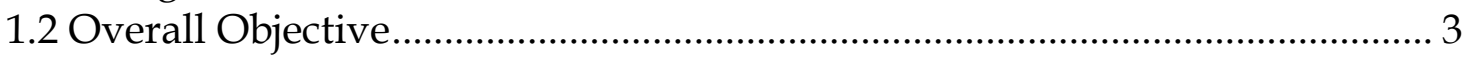

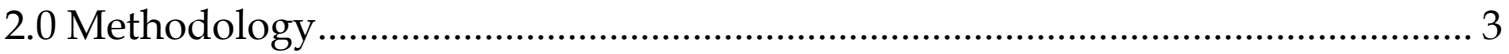

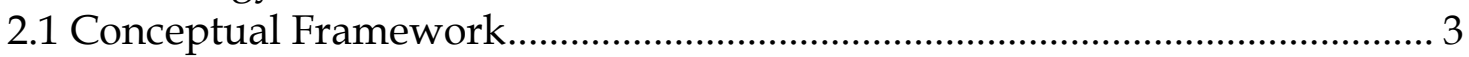

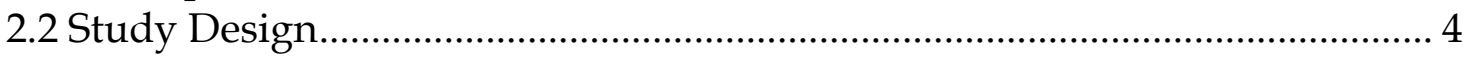

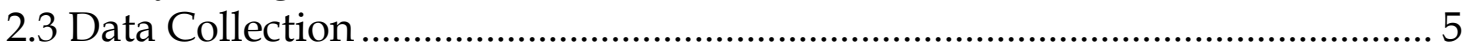

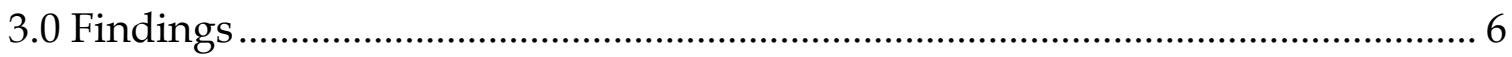

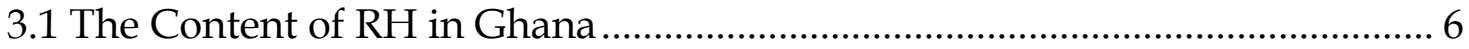

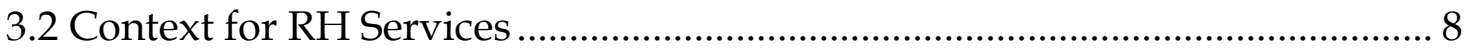

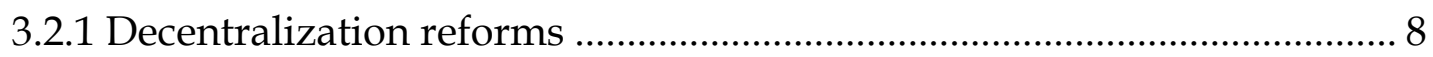

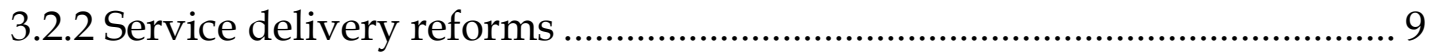

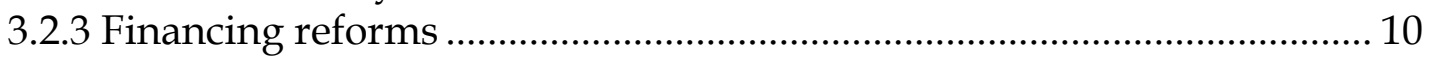

3.3 Priority Setting - Process and Actors ............................................................... 15

3.3.1 National level priority setting $\quad 15$

3.3.2 District level priority setting 17

3.3.3 What influences the selection of priorities at the district level? ............. 18

3.4 Is reproductive health receiving attention at the district level? .................... 21

3.4.1 Is RH a perceived problem at the district level?....................................... 21

3.4.2 The position of reproductive health in the list of district priorities ...... 22

3.4.3 Do the media give attention to RH? ....................................................... 23

3.4.4 Is the RH programme adequately resourced? ......................................... 24

3.4.5 What is the capacity of districts to deliver RH services? ....................... 26

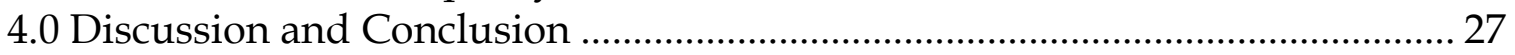

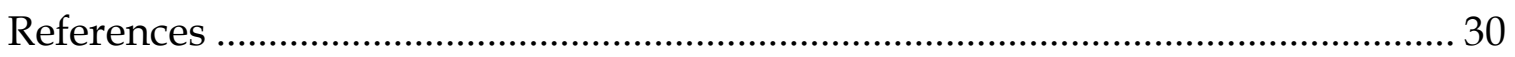




\section{List of Acronyms}

\begin{tabular}{ll} 
ADH & Adolescent Health \\
AES & Awutu-Efutu Senya district \\
AIDS & Acquired Immune Deficiency Syndrome \\
ANC & Antenatal Care \\
AYA & African Youth Alliance \\
BMC & Budget Management Centers \\
CBO & Community Based Organizations \\
CHPS & Community Health and Planning Services \\
DA & District Assembly \\
DACF & District Assemblies Common fund \\
DALYS & Disability Adjusted Life Years \\
DANIDA & Danish International Development Agency \\
DFID & Department for International Development, UK \\
DHD & District Health Directorate \\
DHA & District Health Administration \\
DHC & District Health Committee \\
DHMT & District Health Management Team \\
GDHS & Ghana Demographic and Health Survey \\
GHS & Ghana Health Service \\
GPRS & Ghana Poverty reduction Strategy \\
GOG & Government of Ghana \\
HIV & Human Immune Deficiency Virus \\
HIPC & Highly Indebted Poor Country Initiative \\
HSR & Health Sector Reforms \\
ICPD & International Conference on Population and Development \\
IPT & Intermittent Prevention and Treatment \\
MCH & Maternal and Child Health \\
MDG & Millennium development Goals \\
MOH & Ministry of Health \\
NACP & National AIDS Control Programme \\
NGO & Non Governmental Organization \\
NHIS & National Health Insurance Scheme \\
PMTCT & Prevention of Mother to Child Transmission \\
POW & Programme of Work \\
RCH & Reproductive and Child Health \\
RH & Reproductive Health \\
RHMT & Regional Health Management Team \\
SDHT & Sub District Health Team \\
STI & Sexually Transmitted Infections \\
SRH & Sexual and Reproductive Health \\
SWAp & Sector Wide Approaches \\
\hline &
\end{tabular}




$\begin{array}{ll}\text { TBA } & \text { Traditional Birth Attendant } \\ \text { TT } & \text { Tetanus Toxoid } \\ \text { UNFPA } & \text { United Nation's Population Fund } \\ \text { UNICEF } & \text { United Nation's Children Fund } \\ \text { USAID } & \text { United States of Agency for International Development } \\ \text { WHO } & \text { World Health Organization }\end{array}$




\section{Acknowledgements}

The study team would like to acknowledge the technical review support received from staff of UNFPA/Ghana, Ms. Jane Wickstrom, USAID/Ghana and staff of Frontiers in Reproductive Health Program, Population Council.

During fieldwork, Ms. Nancy Ekyem and Mr. Noble Adiku provided valuable assistance that made the facility assessment possible. Our appreciation also goes to Dr. Arde- Acquah, Dr. Morrison and Dr. John Eleeza who kindly provided indepth information about their regions and districts during the course of the study. We would also like to thank all members of the Ho and Winneba District Health Management Teams as well as the members of the District Assembly Sub Committees on Health for their cooperation and insightful contribution to the study.

We thank Ms. Isabella Rockson and Ms. Angela Gadzepko (Population Council, Accra) and Ms. Joyce Ombeva (Population Council, Nairobi) for their administrative support throughout the study.

Above all, we would like to thank all other individuals not listed here who agreed to participate in this study. 


\section{Executive Summary}

This report outlines results of an in-depth assessment carried out during the period November 2004 - August 2005. The purpose of the assessment was to provide a better understanding of key factors affecting reproductive health prioritization at district level, make recommendation for policy dialogue, advocacy, resource allocation and reproductive health programme implementation. This study assessed whether there is harmony or discrepancy between national and district priority setting for $\mathrm{RH}$, and whether Health Sector Reforms (HSR) facilitate or constrain priority setting for RH at the district level. In particular, the study examined whether districts are or are not connecting to the central process of priority setting and reasons for not connecting.

The study was conducted at the national, regional and district levels. It included two districts: Awutu-Efutu Senya (AES) in the Central region and Ho in the Volta region. Data for the study were gathered through a desk appraisal of key documents, group discussions, in-depth interviews with key informants directly and indirectly involved in the priority setting process, and facility assessment.

This study confirms that reproductive health is a "stated" priority at both the national and district levels. But priority setting is essentially driven at the national level -- the national level sets priorities and districts implement them.

Health sector reforms in Ghana tend to support and reinforce a focus on the RH package at the district level in three ways:

- Organization of services in health institutions makes the provision of RH almost mandatory since all health institutions at the district have RH/FP units that are responsible for safe motherhood and family planning services. This institutional arrangement ensures that reproductive health services stand out as an entity even in the integrated approach to health services in the country.

- The sector-wide approach adopted key RH indicators that form the basis for assessing sector-wide performance and ensuring accountability at the district level. For that reason the dialogue at the sector level is about both RH service delivery and systems development. It is assumed under these circumstances that HSR in Ghana should lead to the delivery of RH interventions. However, findings seem to imply that HSR are not translating into service delivery because of inadequate capacity in terms of drugs, supplies, equipment and service protocols.

- Financing reforms did not discriminate in favor of RH services; nevertheless, since the late nineties the country has been introducing exemptions that have increasingly focused on ANC and supervised delivery. This is to be reinforced under the NHIS programme. 
Ghana is, however, currently facing the challenge of harmonizing a comprehensive definition of RH and the reality of selective implementation at the district level. There is, therefore, a gap between the RH components as stated in the national policy and the components available at the district level. The reality districts face is that they do not have enough capacity to do all that has been defined in the national policy and therefore have to make choices within the institutional arrangements defined in the health sector.

Program managers and service providers tend to focus on aspects of RH consistent with their mission and comparative advantage. Both the public and private health institutions tend to focus on safe motherhood, FP and STI/HIV/AIDS while NGOs tend to focus on the abandonment of harmful traditional practices and promotion of sexual health. The management of infertility and $\mathrm{RH}$ cancers is absent in both districts.

The fact that national level priorities are district level priorities leads us to conclude that the thrust of activities at the district level is about building capacity to implement national priorities rather that selecting priorities per se. Secondly, the challenge facing $\mathrm{RH}$ is not HSR per se but the broad range of RH services and the capacity required to ensure that they are fully integrated into the health system. The contribution of health sector reforms to reproductive health is in ensuring that health systems development under HSR keeps pace with the capacity needed to deliver RH interventions. In the case of Ghana, it appears HSR has so far been unable to do so.

Recommendations for bridging the policy implementation gap include:

- Ensuring that RH advocates participate in national policy dialogue

- Investing in systems development for procurement and delivery of drugs and supplies to the health institutions

- Recognizing that other implementers, in particular NGOs, have a comparative advantage in the delivery of certain components and mobilizing them to deliver these packages to ensure availability of these services at the district level

- Mobilizing District Assemblies to support RH activities. 


\subsection{Introduction}

\subsection{Background}

Ghana has recognized that improved Reproductive Health $(\mathrm{RH})$ Services are important in achieving the goals of the Ghana Poverty Reduction Strategy (GPRS) and Millennium Development Goals (MDG). Reproductive health services are implemented within the framework of the health sector reforms. The Second Health Sector Five Year Programme of Work (2002 -2006) has adopted seven reproductive health indicators, namely; maternal mortality ratio, HIV seroprevalence among the reproductive age, family planning acceptor rates, antenatal care coverage, supervised delivery, post natal care and maternal deaths audited rates as core reproductive health indicators for measuring sector-wide performance.

In recent years, several interventions have been developed for improving reproductive health, which indicate the government's high level of commitment to the issue. These include a National RH Service Policy, Standards and Protocols; maternal death and clinical audit guidelines; capacity building through skills development; supply of equipment; advocacy at all levels, community-based health planning and services; and a selective exemption policy for free antenatal care.

However, despite this level of commitment, maternal mortality still remains high at 214 deaths per 100,000 live births. Family planning acceptance has also remained persistently low with a modern contraceptive prevalence rate of just 13 percent in 1998 and 19 percent in 2003 (GDHS). The proportion of women who give birth with the assistance of a skilled birth attendant, a proxy measure of the risk of maternal morbidity and mortality, is still rather low. Less than half (47 percent) of the births in Ghana are delivered by a health professional (GDHS, 2003).

HIV / AIDS is an emerging challenge to health in Ghana and is feared to undermine all the progress achieved in the health sector if not tackled (MOH \& GHS 2002). The 2003 sentinel survey among women attending ANC clinics shows an HIV site prevalence range of $0.6-9.2$ percent (GHS, 2003).

The fifth MDG has set a target of reducing the maternal mortality ratio to $54 / 100,000$ by year 2015, while the GPRS has set a target of 160/100,000 by 2005 (UNFPA/MOH March 2004). In order to meet these targets, Ghana will have to review strategies influencing these key indicators and modify activities in the second 5 Year Programme of Work (POW) during the coming year.

The key challenge is to ensure that RH is adequately funded and remains a priority at the policy and implementation levels. For instance, a recent review on the role of UNFPA in Sector Wide Approaches (SWAp) suggests that the level of priority setting 
for RH differs between national (policy) and district (implementation) levels (Enyimayew, 2003). Also, anecdotal evidence suggests that district managers may allocate funds away from programs they perceive as having significant vertical funding (for example HIV/ AIDS and adolescent health).

While it is globally acknowledged that SWAp may have facilitated the interaction between $\mathrm{MOH}$ and donors, Jeppsson (2002) has raised a number of issues concerning the nature of the partnership between actors in the SWAp process in a decentralized context. One critical issue that seems not to have been explicitly addressed is whether SWAp affects the power balance and the relationship between the $\mathrm{MOH}$ on one hand, and the district level on the other, and if so how this affects priority setting. Elsewhere, Mayhew et al (2003) have also argued that in contexts where SWAp are implemented alongside decentralization, reforms may impede priority setting for $\mathrm{RH}$ and/or even polarize $\mathrm{RH}$ activities in district plans and actions in part because priority setting is influenced by political and organizational factors that are not considered by current priority setting tools such as Disability Adjusted Life Years (DALYS).

Recent international literature on Health Sector Reforms (HSR) observes that Sexual and Reproductive Health (SRH) is almost invisible in the HSR agenda (Standing, 2002; Hill, 2002; Mayhew and Adjei, 2004). Three major reasons account for this. First, there is a serious language and discourse gap between those participating in HSR and those responsible for SRH that rarely interacts internationally, nationally or locally; when meeting, HSR actors tend to speak in a managerial/technocratic language, while SRH actors tend to speak an advocacy language. HSR discourse focuses mainly on system strengthening interventions, such as financing mechanisms and human resources management, while SRH discourse is pre-occupied with advocating for RH interventions, packages and services. Secondly there is a debatable perception that health sector reformers tend to see SRH as a vertical or special interest program, thus neglecting it, while $\mathrm{RH}$ advocates tend to question the ability of health sector reforms to focus on and deliver RH interventions. The situation is even made more complex by the fact that SRH advocates have not sufficiently understood the importance of engaging in systems reforms while health sector reformers have not understood that reforms will be judged to be successful only if they deliver health interventions including SRH interventions. Thirdly, and more specific to Ghana was a desire by the SRH programme to want to remain semiindependent, retaining its own earmarked funding and specialized cadre (Mayhew and Adjei, 2004).

UNFPA/Ghana and other health sector development partners wanted a better understanding of the key factors affecting $\mathrm{RH}$ prioritization at the district level. They requested a study that would address the following issues: 
- Whether RH is a priority at the district level;

- Whether there is harmony or discrepancy between national and district level RH priorities; and

- Whether HSR facilitates or constrains priority setting for RH at the district level.

The purpose of the study is, therefore, to inform UNFPA, MOH and other health sector development partners on future strategies to ensure that RH is a priority at the district level so that it will be adequately funded. It is expected that UNFPA and other RH advocates in Ghana will use the findings from this study to press for greater focus on $\mathrm{RH}$ at the district level. It will guide the $\mathrm{MOH}$ and other health development partners in the health sector SWAp in negotiating an appropriate balance between concerns for health systems strengthening and improved delivery and quality of RH services. Information generated by the study is also useful in informing decisions on how to reprioritize RH concerns at the district level in order to sustain policy targets.

\subsection{Overall Objective}

The overall aim of the study was to examine facilitating and inhibiting factors in $\mathrm{RH}$ priority setting at the district level, and make recommendations for policy dialogue, advocacy, resource allocation and RH program implementation.

\subsection{Methodology}

\subsection{Conceptual Framework}

The debate on priority setting is about government as an allocator of scarce health care resources involving the selection of health services, programmes or actions that will be provided first, with the purpose of improving the health benefits and distribution of health resources. Ideally, priority setting is perceived as a technical process requiring the quantitative analysis of the burden of diseases, premature mortality and disability losses, the analysis of cost-effectiveness of alternative interventions to control the diseases that cause the largest health losses and then the selection of a package or list of interventions that can be delivered with the available budget through the current health system (Ham, 1996; Bobadilla, 1996). In reality priority setting is more complex than this. The process is frequently influenced by political, institutional and managerial factors.

This study drew on two mutually reinforcing conceptual frameworks: 1) the Walt and Gilson (1994) policy analysis framework ${ }^{1}$ and 2) the Reichenbach's (2002) framework for measuring policy priority ${ }^{2}$.

\footnotetext{
${ }^{1}$ Walt G, Gilson, L. 1994 Reforming the health sector in developing countries: The central role of the policy analysis. Health Policy and Planning 9: 353-370.
} 
The Walt and Gilson framework takes into account the content of policy and/or program, the actors involved, the processes contingent on developing sector priorities and implementing programmes as well as the context within which the priorities or programmes are developed. We looked at the influence of the different actors, the priority setting process, and contextual factors and how these interact to influence priority setting in the health sector at the national and district levels. The Reichenbach's policy priority framework is about whether a specific health issue is receiving attention or consideration on the policy agenda. The framework outlines three ways of measuring attention: direct attention, process attention and political attention:

- Direct attention refers to the commonly used systematic measures of RH status such as incidence data, mortality and morbidity data, DALYS and actual costs.

- Process attention covers the direct and indirect measures of social organizational capacity to address a particular health issue, including physical resources such as drugs, equipment, commodities and supplies, but also technical guidelines and recommendations, treatment protocols and the number of training courses and workshops organized for clinicians and other service providers to develop capacity to address a health issue.

- Political attention measures the extent to which groups or individuals in positions of influence including politicians, civil servants and Ministers, NGOs - academic organizations, women's organizations, medical associations and the media are engaged in advocacy and policy making, raising $\mathrm{RH}$ issues publicly and publishing information.

The two frameworks were combined to provide a comprehensive approach to better understand the priority setting processes. The combined framework was applied retrospectively to understand:

- The content of reproductive health;

- The process of priority setting;

- The influence of the different actors on the priority making processes; and

- How these interact with the contextual factors to determine the level of attention RH receives at the national and district levels.

\subsection{Study Design}

This in-depth assessment used both quantitative and qualitative methods of data collection. The study was conducted at both the national and district levels. It included two districts; AES in the Central region supposed to be receiving earmarked support for

\footnotetext{
2 Reichenbach, L. 2002 The Politics of Priority Setting for reproductive Health: Breast Cancer and Cervical Cancer in Ghana. Reproductive Health Matters, Volume 10 Number 30, November 2002, 47 - 57.
} 
RH from UNFPA and Ho in the Volta region that was not supposed to be receiving earmarked funds for RH. However, after the initial data were gathered it was clear that both districts received earmarked funds from various sources for reproductive health. Therefore a comparative analysis of the two districts on the basis of this criterion was not possible. Consequently, no attempt is made in this assessment to attribute differences between the two districts to earmarked funds.

\subsection{Data Collection}

Data were collected through a desk appraisal of key documents, group discussions, indepth interviews with key informants directly and indirectly involved in the policy setting process, and facility assessment.

The desk appraisal was undertaken to address key questions about the content and context of $\mathrm{RH}$ priority setting. Several documents were reviewed for their content in relation to reproductive health including policy documents, district development plans, annual and quarterly reports of the Ghana Health Service (GHS), aide mémoire for the joint review mission of the Government of Ghana and partners in the health sector, annual health sector performance reports, midterm review reports for the health sector strategic plan, POW and health policy statements, program documents of international technical agencies and NGOs, and local publications. Budgets and

\begin{tabular}{|l|l|}
\hline \multicolumn{2}{|c|}{ Table 1: Actors Interviewed } \\
\hline $\begin{array}{l}\text { Government } \\
\text { Organizations }\end{array}$ & $\begin{array}{l}\text { 1 MOH Key Informant } \\
\text { 2 GHS Key Informant } \\
\text { 1 Reproductive and } \\
\text { Child Health (RCH) } \\
\text { Programme manager }\end{array}$ \\
\hline $\begin{array}{l}\text { Private organizations } \\
\text { \& NGOs }\end{array}$ & $\begin{array}{l}\text { 5 NGOs in Volta } \\
\text { Region } \\
\text { 6 Private Health Care } \\
\text { Organizations }\end{array}$ \\
\hline $\begin{array}{l}\text { Health Development } \\
\text { Partners }\end{array}$ & $\begin{array}{l}\text { UNFPA and 1 WHO } \\
\text { Officials }\end{array}$ \\
\hline Regional Directors & 2 Regional Directors \\
\hline District Directors & $\begin{array}{l}\text { 2 District Directors of } \\
\text { Health Services } \\
\text { (DDHS) }\end{array}$ \\
\hline Service Providers & $\begin{array}{l}\text { Public and NGO } \\
\text { providers }\end{array}$ \\
\hline
\end{tabular}
expenditure records at both district and facility level were also reviewed to generate information on funding for health in general and RH services specifically. Programs of local media stations and print media were reviewed for the past five years (where possible) to assess media attention to reproductive health concerns.

In seeking the views of individuals about priority setting in the health sector, several actors (policy makers, program managers and service providers) at the national and district levels were identified and interviewed from government organizations, private 
organizations and NGOs, health development partners, technical assistance agencies, district directors and service providers (Table 1).

The interviews elicited information on questions about the context, actors, process and political attention. The process of carrying out key informant interviews covered a period of two months.

Key actors from the districts were brought together in a forum to discuss issues related to priority setting for $\mathrm{RH}$ within the context of SWAp in order to elicit group opinions, attitudes, impressions, experiences and suggestions, and to observe the process of interaction and debate between these actors. Four types of group discussions/meetings were organized as follows: 1) 25 members of the District Health Management Teams (DHMT) and 35 members of the Sub-district Health Management Teams (SDHMT), 2) 17 members of the District Assembly (DA), 3) 13 members of the District Health Committees (DHC), and 4) service providers. The group discussions and/or meetings aimed at understanding the priority setting process, context and political attention to reproductive health concerns. A discussion guide was used covering three broad themes including the process and context of priority setting, and political attention to $\mathrm{RH}$ concerns at the district level.

A facility assessment was conducted at 41 public and private facilities in the Ho district and 24 in the AES district that offer maternal and reproductive health services as well as services for specific infectious diseases (sexually transmitted infections, HIV/ AIDS). The aim was to capture issues of availability of resources and support services for different RH components, in terms of direct measurement of social and organizational capacity to address particular RH issues, including physical resources (such as drugs, equipment and other commodities and supplies), infrastructure, technical guidelines and recommendations, treatment protocols, staffing and provider training.

\subsection{Findings}

\subsection{The Content of RH in Ghana}

The RH program in Ghana was adapted from the International Conference on Population and Development held in Cairo (ICPD, 1994). Accordingly, Ghana's Reproductive Health Service Policy and Standards have defined reproductive health as:

"A state of complete physical, mental and social well-being and not merely the absence of disease and infirmity in all aspects related to the reproductive system and its functions and processes. Reproductive health therefore implies that people are able to have a satisfying and safe sex life and that they have capability to reproduce and the freedom to decide if, when and how often to do so." 
The policy calls for universal access to a wide range of services and a comprehensive package of interventions for promoting women's health and well-being, employing a human rights and client-centered approach within a multi-sectoral framework. The specific components of Reproductive Health Services as spelt out in the policy are:

- Safe Motherhood including antenatal, safe delivery, and postnatal care especially breastfeeding, infant health, and women's health;

- Family Planning;

- Prevention and treatment of unsafe abortion and post-abortion care;

- Prevention and treatment of reproductive tract infections, including sexually transmitted diseases and HIV/ AIDS;

- Prevention and treatment of infertility;

- Management of cancers of the male and female reproductive tract, including the breast;

- Responding to concerns about menopause and andropause;

- Discouragement of harmful traditional practices that affect the reproductive health of men and women such as female genital mutilation; and

- Information and counseling on human sexuality, responsible sexual behavior, responsible parenthood, pre-conception care, and sexual health.

While the Policy spells out a broad package of RH, the Reproductive and Child Health Unit (GHS) annual reports have tended to provide a more limited list of RH components. These include:

- Safe motherhood including infant health

- Family planning

- STI/HIV/AIDS prevention and management

- Postabortion care

- Prevention and management of cancers of the reproductive system.

The focus of RH in the district plans and the interviews with key stakeholders tended to infer that an even more limited package is being delivered in reality. The common components of reproductive heath services available at the district level were:

- Safe Motherhood including antenatal, delivery and post natal care,

- Family Planning, and

- STI/HIV/AIDS prevention and management. 
A service availability mapping at the district level further reinforced the limited scope of reproductive health services in health facilities (Table 2). In general health facilities in the two districts provide post-abortion care, family planning, STI/HIV/AIDS and safe motherhood services. Services related to the promotion and advocacy for sexual health and abandonment of harmful traditional practices are made available through the NGO sector. Programmes and services for the management of infertility, cancers and menopause were not available in either district. Special programmes related to HIV / AIDS targeting adolescents were offered in almost all facilities. However, less than 5 percent of the facilities in both districts offered programs targeting adolescents for antenatal care, postnatal care, STI and family planning.

\subsection{Context for RH Services}

Ghana initiated health sector reforms (HSR) in the 1980s in response to weak management systems, uncoordinated, fragmented and competing donor driven project support. The HSR were then described as "a sustained process of fundamental changes in national health policy and institutional arrangements, guided by government and designed to improve the functioning and performance of the health sector and ultimately, the health status of the population (Akosa et al, 2003). The HSR were guided by five over-arching principles: integration, decentralization, partnerships, ownership, and common financing (Addai and Gaere, 2001). From the interviews and documents reviewed, the key reform elements influencing reproductive health priority setting were reforms in decentralization, service delivery and financing.

\subsubsection{Decentralization reforms}

A major institutional reform under HSR has been decentralization, involving the transfer of decision-making authority and management of health services from the central ministry of health to regional and district levels. The health sector's decentralization programme was further reinforced in 1997 with the establishment of the Ghana Health Service (GHS) as an agency of Government responsible for service delivery. The Ministry of Health is responsible for stewardship of the entire health 
sector including policy formulation, resource mobilization and allocation, coordination, monitoring and evaluation.

Under the decentralized arrangement, the Ministry of Health determines the policies and priorities for the health sector and communicates them to the Ghana Health Service and other relevant Partners. The Ghana Health Service then develops policy implementation guidelines for the regions and districts. The regions then coordinate the development of district plans and provide supportive supervision to districts to implement the plans. Districts are mandated to develop and implement operational plans in line with national policy and priorities.

To reinforce the decentralization programme, District Health Management Teams (DHMT), led by a public health physician, have been established in all districts to plan, implement, monitor and coordinate service delivery. Financial management has also been decentralized through the creation of Budget Management Centers (BMC).

District health management teams were found to have flexibility in decisions on how to allocate funds to activities including reproductive health activities based on the prevailing evidence and the expressed needs of staff and other service providers. District directors also have the authority to make transfers within budget lines and push money to support specific programmes. Furthermore, districts have the authority to mobilize additional funds from donors and to collaborate with others to carry out RH activities.

The key challenge to decentralization is ensuring that districts provide adequate attention to national priorities in their programmes. This challenge is mitigated through a combination of effective and participatory leadership at the district level and guidance from the regional and central level. Further, districts are held accountable to national priorities by requiring them to report on the sector wide indicators and targets, which include those for reproductive health.

\subsubsection{Service delivery reforms}

Decentralization of health services went hand in hand with attempts to move from vertical projects and programmes to an integrated form of service delivery. In line with this approach, the $\mathrm{MOH}$ defined a package of interventions to be delivered by the network of health institutions. Maternal and Reproductive Health Services are included in the list of priority health interventions defined in the POW. The specific role of each level of health services in the provision of reproductive health services is further specified in the reproductive policy and standards.

The management support systems including systems for procurement and financial management have also been re-organized functionally to support the integrated delivery of health services. For example, under a vertical programme, the headquarters 
was responsible for managing the cadre of staff, procurement and distribution of essential logistics and also for planning and implementation of health programmes and services.

Following the adoption of the decentralized integrated services, District Health Management Teams (DHMT) became responsible for the planning, organizing, implementing, monitoring and reporting on an integrated package of health programs and services. The DHMT are allocated budgets for procurement of inputs for the implementation of district health plans. DHMT are also responsible for aspects of the management of human resources including posting and performance management, but excluding hiring and firing $(\mathrm{MOH}, 1998)$.

The challenge of integration is ensuring attention to the individual programmes as entities within the health sector. Even though all programmes share this concern, the organization of service delivery within institutions seems to minimize this threat for some components of the reproductive health package. For instance, all the public health facilities have maternal health units responsible for the provision of family planning and safe motherhood services. These units are expected to ensure continuous attention to these components of reproductive health in the planning and delivery of health services. However, there are no units focusing on infertility, cancers, menopause, andropause, advocacy against harmful traditional practices and for sexual health. By implication these services have been integrated into oblivion in both districts.

\subsubsection{Financing reforms}

Ghana has been implementing a number of financing reforms aimed at increasing overall resources to the health sector and ensuring equitable allocation. These reforms include the introduction of user fees and related exemption policy and the sector wide approach. Ghana is presently introducing a national health insurance scheme whose primary objective is to replace user fees.

\section{User Fees, Exemption Policy and Health Insurance Scheme}

The Government of Ghana introduced user fees into the public health system in 1983. The user fees were intended to fill the financing gap in the provision of comprehensive health services and contribute to improving quality of health services. The user fee policy covers the cost of clinical care including consultations, drugs, non-drug consumables and admissions. All maternal health services provided in public health institutions, with the exception of immunization of pregnant women against tetanus and family planning, attracted user fees under this policy.

To reduce the financial barriers to services while retaining the positive elements of user fees, an exemption scheme was instituted alongside the user fees (GHS, 2003). The key elements of the exemption policy are to promote the use of services of public health importance that might otherwise be used suboptimally while concurrently minimizing 
the cost of care to the poor. Government prioritized the delivery of safe motherhood services and provided exemptions for antenatal care and deliveries in addition to family planning and immunization.

At the time of the study, Ghana was introducing a national health insurance scheme. It is anticipated that the health insurance scheme will replace both the user fees and exemptions. The goal of the scheme is to assure universal access for all residents in Ghana to an acceptable quality package of health services, including RH services. The National Health Insurance scheme provides for the delivery of health services at the district level. The minimum benefit package to be provided under the NHIS includes the following RH interventions:

- Antenatal care

- Deliveries

- Postnatal care

- Caesarian section

- Postnatal care

- Management of emergency obstetric and gynecological conditions

- Breast cancer and cervical cancer management

- Management of STI/HIV/AIDS (excluding ART)

Though family planning, confirmatory HIV/AIDS testing and immunization are not included in the benefit package under the National Health Insurance Scheme, they will be provided free of charge to clients through the government's public health programmes. Treatment for Infertility, menopause, andropause, anti-retroviral therapy and male reproductive cancers are excluded from both the NHIS benefit package and the public health financing. The package is also silent on PMTCT even though a broader definition of the ANC and delivery packages could include PMTCT.

\section{Sector-Wide Approaches (SWAp)}

In 1997, Ghana adopted the SWAp to health delivery. Under this approach, the Government and Development Partners agreed to a common POW, pooled funding, and common management arrangement. The Ministry of Health also institutionalized a policy dialogue with partners.

\section{The Programme of Work}

The underlying feature of the health SWAp is for all partners in the sector to work towards a common vision. A five-year POW (5YPOW) 2002-2006 has been developed and agreed to between the Ministry of Health and development partners. The 5YPOW spells out the vision, priorities, strategies, targets, resource envelope, and resource allocation criteria for the sector. The POW has five strategic objectives called strategic pillars which are to: 1) improve quality of health delivery; 2) increase access to health services; 3 ) improve efficiency of health service delivery; 4) foster partnership in improving health and; 5) improve financing of the health sector. 
The POW is a result of information gathering, studies, and nationwide consultations with key providers, consumers, civil society groups, development partners, and Government stakeholders. The POW outlines ten priority health interventions including reproductive health. These have been designated priorities because of their potential or actual impact on health or because of the disparities in health outcomes between regions. Others have been selected because they are targeted for eradication or because of their impact on household resources, particularly for the poor. To a great extent, the focus, priorities and targets have been influenced by the Government's response to the development agenda as spelt out in the Ghana Poverty Reduction Strategy (GPRS). The GRPS highlights three priority objectives for the health sector:

\section{Priority Health Intervention, POW 2002-2006}

- HIV/AIDS/STI

- Malaria

- Tuberculosis

- Guinea worm

- Poliomyelitis

- Reproductive, maternal and child health

- Accident and emergencies

- Non-communicable disease

- Oral health and eye care

- Specialist services including psychiatric care

- Bridging equity in access to quality health and nutrition services

- Ensuring sustainable financing arrangements that protect the poor and

- Enhancing efficiency in service delivery.

The GRPS further recognizes that health, and specifically HIV / AIDS are affected by actions of a range of other sectors. It also draws attention to the need to target vulnerable and excluded groups (such as women, children, disabled, elderly and people living with HIV/AIDS) with basic services.

The POW also aims to respond to key international development targets that Ghana has signed on to, such as the MDGs, the ICPD, and the Abuja declaration. Indeed, these targets have been translated into national targets and have further been translated into regional and district level targets to guide/inform local priority setting in a decentralized system.

Each year the Ministry and Health Partners develop an annual POW that captures the priorities for a particular year. The annual POW is developed after a review of progress made in the implementation of the 5YPOW. A review of the annual POW (2002 - 2005) shows that RH has been a national priority every year. A number of policy interventions relevant to RH have been introduced incrementally in the POW. These are exemptions on deliveries, a budget line for contraceptives to ensure contraceptive security, HIV/ AIDS and an adolescent health program. 


\section{Funding arrangements}

Another component of the SWAp is the pooling of funds to support implementation of the POW. Currently, six of the fifteen official donors in the health sector have pooled funds. These are DANIDA, DfID, European Union, Netherlands, UNFPA and World Bank. In 2004, 58.9 percent (70.34 million USD) of the total expected donor inflows from development partners were pooled (MOH, 2004).

All development partners in the health sector, including those pooling funds, also earmark funds to support the POW. In 2004, about 14.6 percent of the total earmarked funds were from Partners that had also pooled funds. The major partners earmarking funds to support reproductive health activities are UNFPA, USAID, UNICEF and WHO. The UN agencies use the Ministry of Health systems for disbursement of funds, whilst USAID manages its own funds.

The health sector resource envelope as captured in the POW includes funding from the Government of Ghana, donors (both pooled and earmarked), Internally Generated Funds ${ }^{3}$ and inflows from Highly Indebted Poor Country Initiative (HIPC). All sources of funds except earmarked funds are included in the allocations to the district for planning. A needs-based criterion is used to allocate funds to districts based on district population, nearness to regional capital, district deprivation, number of health facilities, district disease burden, as well as hospital utilization. Earmarked funds are not included because it is usually difficult to predict their disbursement. Districts develop specific proposals to access earmarked funds during implementation.

Funding for RH comes from all the four sources of funds including earmarked funds, channeled through GHS or going directly to the districts. The experience with earmarking funds within the health sector is mixed. First, there is feeling among senior program managers that $\mathrm{RH}$ could lose out from pooling of funds and for that reason earmarked funding for RH should continue. The main reason for this is the delay in government disbursement and procurement procedures. Secondly, other senior managers at the national level felt that earmarked funding for $\mathrm{RH}$ did not influence priority setting at the national level; instead earmarked funds tend to distort the funding arrangements and resource flow at the lower level. Overall, the impression was that $\mathrm{RH}$ is benefiting from the combination of earmarked and pooled funding arrangements.

The context of the health SWAp is, however, changing. At the time of the study, the Government had instituted multi-donor budget support mechanisms with development partners considering using budget support as the instrument for support to the sectors.

\footnotetext{
${ }^{3}$ Funds generated from user fees in facilities
} 
Budget support is a form of quick disbursing programme aid which is channeled directly to government, using local accounting systems and is linked to sector or national policies rather than specific project activities. The debate about budget support is a macro-level one and mainly focuses on how to allocate resources between sectors to achieve the national development goals and international targets that Ghana has signed on to, rather than allocation within a particular sector.

The concern among senior managers within the health sector is that the sector may lose out under the budget support system. However, the Ghana Poverty Reduction Strategy, the 2005 Presidential Sessional address and the 2005 Budget statement to Parliament identify health as a key priority of Government that would continue to attract attention. For example in 2005, Government projected to spend about 15 percent of the recurrent budget on health. Government is also committed to maintaining the integrity of the health SWAp at least in the medium term.

The implications of the changing financing context on the health sector and RH in particular as seen by managers is for the health sector to improve its negotiation with the Ministry of Finance and Economic Planning to sustain (or increase) funding under budget support to the sector. Concurrently, the resource allocation within the sector needs to be improved to ensure that priorities are adequately funded.

\section{Common management arrangements}

A common management arrangement and code of practice have been agreed to between the Ministry of Health and the donors pooling funds within the sector. Under this arrangement, partners contributing to the health fund agree to use government systems for disbursements, procurement and accounting for funds. These systems are also extended to earmarked funds that are allocated through the Ministry to the districts.

Some development partners interviewed felt that donors earmarking funds should use parallel systems for disbursements, procurement, accounting and reporting. On one hand, donor managed systems tend to be faster and more responsive to programme requirements such as procurement of equipment, supplies and logistics, as well as to donor accountability requirements. Unless explicitly included in proposals, the implementation of programmes under donor earmarked funding arrangements does not contribute to strengthening the capacity of the health system. Conversely, they sometimes undermine systems development and tend to increase the transaction cost.

\section{Policy Dialogue}

The policy dialogue established under the SWAp creates the platform for identifying sector priorities. The $\mathrm{MOH}$ and its partners have agreed to and institutionalized arrangements for policy dialogue. The dialogue includes monthly partners' meetings, quarterly business meetings and half yearly 
summits. The monthly partners' meetings and quarterly business meetings are for reflections and updating Partners on progress in implementation arrangements. The summits endorse the POW, and monitor progress to identify priorities and allocate resources. Through the policy dialogue, the health sector has engaged a wide range of stakeholders in the development and implementation of the health sector plans. The outcome has been a Program of Work (POW) that many stakeholders can identify with (Enyimayew, 2003).

\subsection{Priority Setting - Process and Actors}

\subsubsection{National level priority setting}

National priorities for the health sector are set by the Ministry of Health and health partners at the health summit and expressed in the POW and aide mémoire. The summit brings together key stakeholders in the health sector and is the time when the principals of development partners come into the country to participate in sector policy dialogue. The health summit has four broad components.

The first summit of the year is the review summit. It is held after a comprehensive review of the POW. This review has three parts. The first is the internal and self review of the contribution of each Budget Management Center to achievement of the targets in the sector. All districts review their achievements against targets and organize performance hearings. The first summit also includes a field component to provide the principals the opportunity to interact with key health managers at the local level so as to understand and contextualize program implementation issues to be discussed during the meetings.

The second component of the summit is the scientific session. This session provides a forum presenting and discussing research papers and in-depth reviews that are relevant to the theme of the summit and answering specific questions related to the implementation of the POW. Each year about three to four thematic areas of strategic importance to the implementation of the POW are identified and reviewed. Our findings confirm that $\mathrm{RH}$ is among the themes that have been presented and discussed. For example in 2004, an in-depth review into the health sector response to maternal mortality was commissioned. Other reviews included health sector performance as an analysis of DHS, contraceptive prevalence study and repositioning family planning. In 2005, an in-depth review of how district plans respond to the national level priorities was commissioned.

The third component is the program review session, which focuses on discussing the POW, its strategies, priorities and sector performance. All the above three components are open to all invited stakeholders including GHS headquarters staff, regional directors, other sector ministry representatives, development partners, coalition of NGO 
representatives, and private practitioner representatives. This team synthesizes the reports of the first and second reviews and presents recommendations that are negotiated at the summit.

The last component of the health summit is the business meeting, which is attended by delegates of the $\mathrm{MOH}$ and funding partners. It is at the business meetings that sector priorities are negotiated and agreed to after drawing on the body of evidence and discussions that have emerged from the earlier three components. The agreements in the business meeting are summarized into an aide mémoire that is endorsed and signed by the $\mathrm{MOH}$ and only health partners pooling funds. In other words the $\mathrm{MOH}$ and health partners that pool funds are the ones who make the final decisions regarding sector priorities. Some national level respondents were of the view that:

"Partners are more interested in global priorities being translated into national priorities".

Until a year ago, there was no advocate for reproductive health signing the aide mémoire, simply because such representatives were not invited. However, this situation has changed with UNFPA signing the aide mémoire and beginning to influence the decisions of the summit significantly. In October 2003 UNFPA commissioned a study on UNFPA's role in health SWAp in Ghana. The study recommended that UNFPA should engage more actively in the health SWAp. Since then, UNFPA's participation in the SWAp has been increasing. In 2004 UNFPA contributed funds to the health fund, i.e. UNFPA joined the pooling funding arrangement, and by implication became an active participant in the health policy dialogue.

Currently UNFPA is member of the planning committee that determines the agenda for the health summit; UNFPA sits at the business meetings and also participates in negotiating and signing of the aide mémoire. In 2004 UNFPA worked with the $\mathrm{MOH}$ and other partners to commission a study on the health sector's response to maternal mortality. Thus, UNFPA's role in the sector dialogue has contributed to the increased attention paid to $\mathrm{RH}$ issues. An aide mémoire review showed that reproductive health (apart from HIV / AIDS) did not feature in any aide mémoire prior to 2004. However, 2004 was the turning point for reproductive health focus/attention, where specific summit recommendations stated the:

- Training of community health officers to provide midwifery services (June 2004)

- Strengthening of services related to STI and condom use (Dec 2004)

- Strengthening of MCH and EOC services (June 2004) 
Consequently, the attention being given to reproductive health during the summit and reflected in the aide mémoire has increased in the last two years.

\subsubsection{District level priority setting}

District level priorities are determined during the annual planning and budgeting process, which involves three steps:

- Ministry of health issues guidelines for planning. Typically the guidelines include the sector priorities and targets, resource envelope and budget ceilings and tools and process for planning. The guidelines are developed after reviewing the lessons from the review of the annual POW, progress made towards achieving targets defined in the five-year POW, and the overall development priorities of government.

- Cascading planning workshops are then organized at the national, regional and district levels to orientate managers in the priorities for the year and in the tools and process for planning.

- Each district then develops its plan in line with the guidelines from the Ministry of Health and after taking account of the district's own peculiarities. The district plans are then peer reviewed at the regional level and then consolidated into a national plan.

During the planning process, districts review the various components of service delivery such as clinical care, public health services including reproductive health as well as essential support services. Districts also review progress and challenges in the previous year, define district targets in the light of national priorities and targets, identify activities to be implemented and cost these activities.

The key stakeholders in district priority setting are:

- District Chief Executive and District Assembly responsible for political administration of the district

- District Health Management Team responsible for coordination of health activities and management of the district health budget

- Providers of health services, both public and private providers, including NGOs

- Civil society including chiefs and elders of the district

However, in both study districts, the District Health Management Team is responsible for setting the health priorities of the districts. The process is almost limited to staff of the Ghana Health Service with little or no opportunity for the participation of district assemblies, civil society, NGOs and private providers in the priority setting process operating at the district level. As stated by one district assembly member:

"We are on the ground and know all the problems that occur here. Therefore our voices should be heard, but this does not happen." 
Focus group discussions with members of the District Health Committees of the Ghana Health Service revealed that they had recently been established in both districts and did not seem to have played a major role in determining district priorities. For example, the Ho district health committee members said they were new, no Terms of Reference had been given to them, their role had not been clarified to them, and they had not met since their inauguration over a year ago. Similarly, the AES committee said they have not participated in any DHMT meeting where priorities are set, and had not met the District Director of Health Services since their inauguration over a year ago. When asked whether they knew of the POW, both committees said they had not seen the health sector POW.

Consequently, priority setting for health at the district level heavily depends on the group dynamics within the District Health Management Team rather than other actors. In this interaction, the public health nurse is the key advocate on reproductive health issues. FGDs with district assemblies, district health committees and NGOs revealed that they play minimal role in setting priorities.

\subsubsection{What influences the selection of priorities at the district level?}

National priorities for the health sector are set by the $\mathrm{MOH}$ at the Health Partners Summit and expressed in the POW and aide mémoire that come out of the summit. Even though it is the intention of the $\mathrm{MOH}$ to involve all stakeholders in the summit and thus in setting of priorities, in reality this does not happen. The participation of the district managers and indeed other stakeholders such as NGOs, private sector, professional groups, members of parliament and select committees on health has been very limited. The summit, however, draws on the body of evidence emerging from the annual review process. Consequently, the key stakeholders determining the national priorities are the $\mathrm{MOH}$, their Development Partners and the GHS. The business meeting of the summit is where the decisions on priorities are negotiated.

Interviews with district managers show that three main factors influence priority setting at the district level. The most common influence mentioned was national level priority, followed by district level peculiarities and then the amount of earmarked funds available.

\section{National Level Priorities}

National level priorities drive district priorities. According to the district respondents, priorities are determined at the national level and then they become district level priorities. When asked whether national level priorities were acceptable to districts, district managers in both districts stated that national level priorities were very acceptable. In the words of one senior manager: 
"Priorities are determined for us from above and because we are part of the health sector funded by government we have to take them on."

However, several respondents at the district level were concerned that they do not influence the process of setting national priorities. The general feeling among district managers is that participation in national priority setting is selective and minimal. As stated by one district director:

"District Directors don't sit with national level Directors at a round table any say let's look at priorities for the year. Even at the national and regional annual reviews they do not call on all of us but select one or two from districts where they may have special interest. ... Therefore, even at that level, not all of us are represented. Most people will feel they are involved if they attend stakeholder meetings where everyone is brought on board to contribute but in reality this does not happen"

The involvement of the district directors in the health summit where national priorities are determined was described as indirect and limited to submission of sub-district and district annual report that get consolidated into the sector review report that forms the basis for discussions during the health summit.

\section{Local Level Peculiarities}

Local challenges also influence the district priorities. Respondents indicated that some of their priorities came directly from the districts, which they serve, and are added on to national priorities. In situations where district level priorities conflict with national priorities, the national priorities take precedence over district priorities. Where the national priorities are not problems within the districts, districts exclude such priorities from their list of priorities. One district director's view;

"National and regional (priorities) are important but they don't override our district specific priorities. Even if my district has priorities that are not highlighted at the national level I have the mandate to add them on to mine as a District Director, because my mandate is to improve the health status of the people in my district. The onus of responsibility would be to commit resources to that area and I think I will be justified in doing that."

Districts adapt national priorities to their situation after reviewing them for relevance to their local context. In the words of one district manager:

"When they bring national priorities, you ask yourself, these things they are talking about, how do they affect us? Do we have any problem in that area? For example, if there is a national priority.... And you don't have that problem, what you do is look out for it ... so your job would mainly be 
surveillance. If it is a problem in your district, then you draw an itinerary to curb it."

\section{Earmarked Funds}

UNFPA has been providing earmarked funds to support reproductive health through its AYA project to the Central Region but not to the Volta Region. As a result, only one of the study districts (AES) benefited from earmarked funds.

Respondents from the AES district commented that earmarked funds from UNFPA for Reproductive Health:

- Arean important source of funding for RH activities; even though the proportion of earmarked funds received by the district is small compared to the total budget, earmarked funds are an addition to the budget and by their very nature are available to support implementation;

- Serve to boost sexual and reproductive health services within the decentralized system, as they tend to focus on specific programme activities such as training

- Influence priority setting and resource allocation at the district level by ensuring that more attention is given to $\mathrm{RH}$ activities at the district level.

Earmarked funds also take key managers away from other priorities. As lamented by one district manager:

"Of course earmarked funds influence priority setting, they come and sway us off other priorities."

There was also a concern by district managers that the flow of earmarked funds was too unpredictable making it very difficult to implement programmes. Earmarked funds were also blamed for being fragmented, to the extent that it compromised on-going integrated programmes. The overall view was that earmarked funds drive planned programmes out of balance. For this reason some district managers are reluctant to accept earmarked funds. As remarked by one manager:

"The way things are moving here, should anybody come and say they want to do A, I personally will be able to say I can't now, but can I have the money to do B or go and wait and come back... I am not afraid to refuse funds."

At the regional level, managers argued that they do not see a clear contribution of the earmarked funds to performance. Their concern was that earmarked funds did not necessarily translate into better health outcomes as the difference in service outputs between the districts with and without was not significant. 


\subsection{Is reproductive health receiving attention at the district level?}

The study sought to establish empirically whether reproductive health was receiving adequate attention at the district level. The starting point was to determine whether district managers perceived $\mathrm{RH}$ to be a problem and if so to assess the attention accorded reproductive health in the district. Specifically, the study assessed the attention given to reproductive health at the district level from the following dimensions:

- Do district managers perceive RH to be a problem?

- What is the place of RH on the list of district priorities?

- How much attention do the media in the district give to RH?

- Is the RH programme adequately resourced?

- What is the capacity of districts to deliver RH services?

\subsubsection{Is RH a perceived problem at the district level?}

It is generally assumed that people will do something about things they believe to be problems. Related to this, managers were asked whether they perceived $\mathrm{RH}$ to be a problem. Table 3 summarizes the consensus position from in-depth interviews with regional and focused group discussions with District and Sub-district health management teams.

\section{Table 3: Regional, District and Sub- District Managers' Perceptions of Reproductive Health Problems}

\begin{tabular}{|l|c|c|c|c|c|c|}
\hline Components & $\begin{array}{c}\text { Volta } \\
\text { Region }\end{array}$ & $\begin{array}{c}\text { Ho } \\
\text { District }\end{array}$ & $\begin{array}{c}\text { Winneba } \\
\text { Sub-district }\end{array}$ & $\begin{array}{c}\text { Tsito } \\
\text { Sub-district }\end{array}$ & $\begin{array}{c}\text { Kpetoe } \\
\text { Sub-district }\end{array}$ & $\begin{array}{c}\text { Kasoa } \\
\text { Sub-district }\end{array}$ \\
\hline Antenatal care & + & - & - & + & - & - \\
\hline Safe delivery & + & + & - & + & + & - \\
\hline $\begin{array}{l}\text { Postnatal care/ breast } \\
\text { feeding \& infant care }\end{array}$ & + & - & + & + & + & - \\
\hline Family planning & + & - & - & + & + & + \\
\hline STI/ HIV/ AIDS & + & - & + & + & + & + \\
\hline $\begin{array}{l}\text { Unsafe abortion and } \\
\text { post abortion care }\end{array}$ & + & + & - & + & + & + \\
\hline Infertility (cervical, & - & + & - & - & - & + \\
\hline $\begin{array}{l}\text { Cancers } \\
\text { breast, testicular and } \\
\text { prostate cancers) }\end{array}$ & + & - & - & + & + & + \\
\hline Menopause health, & + & - & - & + & + & + \\
\hline $\begin{array}{l}\text { Harmful traditional } \\
\text { practices }\end{array}$ & + & - & - & + & & + \\
\hline $\begin{array}{l}\text { Sexual } \\
\text { parenthood, \& pre- } \\
\text { conceptual care }\end{array}$ & & + & & + & & + \\
\hline
\end{tabular}

$(+)$ A perceived problem and $(-)$ is not a problem 
- All implementers consider STI and HIV/AIDS to be problems;

- Most implementers consider safe delivery, postnatal care and family planning, unsafe abortion and postabortion care to be problems; and

Less than half of implementers consider menopause, infertility, human sexuality and harmful traditional practices to be problems.

The study also sought to determine how problems were defined within the districts. For example:

- In the Kasoa sub-district, ANC, PNC and safe delivery are not perceived to be problems because the sub-district providers have been trained in safe motherhood. The Kasoa sub-district team sees few teenagers coming in for post-abortion care and therefore do not think post abortion care is a problem. Conversely, FGM, which is commonly seen among immigrants in the community, is considered a problem.

- In Tsitoe and Kpetoe sub-districts, teenage pregnancies and illegal abortions are problems because they are observed in clinics.

- From the HMIS reports in Ho, safe motherhood, and abortions and postabortion care are problems while breastfeeding is not.

- In Winneba sub-district, HIV is a problem because the prevalence is about $5.4 \%$, and teenage pregnancy is declining because of the presence of counselors in the district.

- Generally, cancers and infertility are not problems because not too many cases are seen or picked up by the facilities either because health education campaigns have not been mounted or the caliber of staff at the sub-district and district levels does not have the capacity to diagnose them.

District and sub-district managers mentioned the use of data such as disease prevalence, ANC, PNC and supervised delivery coverage rates to inform their selection of problems.

\subsubsection{The position of reproductive health in the list of district priorities}

Again regional, district and sub-district implementers were asked whether they have their "own" priorities and how reproductive health featured in these priorities.

All districts reported to have their "own" priorities. In Ho, the district priorities included leishmaniasis, child survival, supervised deliveries, and stemming the brain drain of health workers. In AES, the priority is to increase access to services including access to obstetric emergency care. Other priorities included increasing community awareness to RH and improving the skills of TBA.

When asked whether RH is an important priority, regional, district and sub-district managers unanimously said that RH significantly features in their priorities. According to one respondent: 
" $R H$ is very important because if you want to determine the health status of an area, all you need to do is just look at maternal health. From looking at reproductive health and maternal health you can tell if a district is healthy or not."

A review of the district plans confirmed that RH featured extensively in public health programmes, where planned activities include adolescent reproductive health, maternal mortality, family planning, TT2, neonatal health, baby friendly institutions, Vitamin A, STI/HIV/AIDS control, malaria control and health education. District managers, however, expressed concerns over the fact that even though RH deserved and received attention in their district it covered a broad range of services/components.

\subsubsection{Do the media give attention to RH?}

Both study districts had radio stations i.e. Volta Star Radio in Ho and Radio Peace FM in Winneba. The radio programmes are intended to reach as many communities and individuals as possible in and around the districts with a package of valuable health messages. The object of these presentations was to enable individuals to make informed choices and decisions about their health. The content of the radio programmes in both districts was, therefore, reviewed to determine the attention given to $\mathrm{RH}$ issues.

Over the period 2001-2004, the media in both districts presented a total of 137 reproductive health topics; 41 of these were aired by Volta Star Radio in Ho district and 96 aired on Radio Peace FM in AES district. Depending of availability of theme experts and radio presenters, health programmes were broadcasted weekly and bi-weekly in Ho and AES, respectively. Some of the topics featuring on radio include:

- AIDS prevention

- Abortion and postabortion care

- Life choices on family planning

- Safe Motherhood

- Malaria control in pregnancy using IPT

- Adolescent health programme

- STI management

- Information on human sexuality, responsible sexual behavior and sexual health

- Abnormal vaginal bleeding

- Vasectomy

In 2004, the Central Regional health directorate also organized press conferences for 12 journalists covering Family Planning, Life Choices and Safe Motherhood. This was to equip the print and electronic media with vital health information to enable them help educate the masses on issues bordering on public health activities. 


\subsubsection{Is the RH programme adequately resourced?}

The overall health sector budget for 2004 was 1,449,461,999,999 Cedis (Annual POW 2004; 9,000 Cedis $=\$ 1$ ). Budget allocations are included in the Table 4. Funding for service delivery including RH services falls under the Ghana Health Services budget to the districts, which just a proportion of the 68.9 percent is allocated. Of this, 7.6 percent was retained at the GHS Head Quarters, 9.2 percent went to the Regional Health Services (RHS), 5.95 percent to psychiatric hospitals and 46.45 percent $(457,264,210,676)$ went to the district health services; shared among 138 districts across Ghana.

\begin{tabular}{|l|c|c|}
\hline \multicolumn{3}{|c|}{ Table 4: Health Sector Budget Allocation -2004 } \\
\hline Levels & Actual & Percentage \\
\hline Ghana Health Services & $639,259,608,276$ & 68.89 \\
\hline Ministry of Health & $575,303,836,553$ & 11.13 \\
\hline Teaching Hospitals* & $131,396,456,771$ & 9.53 \\
\hline Training Schools & $68,119,442,556$ & 5.91 \\
\hline Subvented organizations & $26,977,635,602$ & 2.81 \\
\hline Innovations fund & $1,404,525,095$ & 0.29 \\
\hline Civil servants exemptions & $7,000,495,146$ & 1.44 \\
\hline Total Health & $1,449,461,999,999$ & 100 \\
\hline
\end{tabular}

${ }^{*}$ Tamale $(9.3 \%)$, Komfo Anokye (6.6\%) and Korle Bu (4.3\%)

However, the district health plans do not provide disaggregated data on budget allocation and expenditure across programmes. Instead, the plan is organized around the five strategic objectives of the health sector and the budget is summarized by line items i.e. by allocation to human resources (item 1), administration (item 2), service (item 3), and investments (item 4). It was, therefore, not possible to determine the proportion of the district budget allocated to reproductive health activities. However, it can only be anticipated that overall resource allocation to service delivery including $\mathrm{RH}$ as a proportion of health sector budget is rather small.

Non-central sources of funding are limited at the district level and include funds from the District Assemblies Common fund (DACF), CBOs and NGOs. Actual budgets for NGOs and CBOs were not available but a sizable number of existing NGOs in the districts were delivering services in RH. In Ho district, 5 of the 20 NGOs were delivering RH services and 3 of the 5 NGOs and 15 CBOs in the AES district were doing the same. The two districts also reported receiving direct donor support in kind (contraceptives, test-kits, and vehicles for supervision).

User fees are an additional source of funds at the district level and are included in the health sector budgets. Fees go into revolving drug funds and contribute about $20 \%$ of total spending at the district level. Although income from user fees is small, it does enhance decentralized decision-making since it remains under district and facility 
jurisdiction. The study could also not estimate the proportion of user fees collected from the provision of Reproductive Health Services. This is because the financial report does not indicate the sources of user fees by programmes.

Service utilization was nonetheless used as a proxy indicator of the effort that goes into reproductive health services. The proportion of in-service training allocated to reproductive health issues was also reviewed as a proxy for the relative investments in RH. Over half of outpatient and inpatient services offered in both Ho and AES district during the period $(2001$ - 2004) were reproductive health-related (Table 5).

\begin{tabular}{|c|c|c|c|c|c|c|c|c|}
\hline \multicolumn{9}{|c|}{$\begin{array}{c}\text { Table 5: Reproductive Health Service Utilization and } \\
\text { District Level (2001-2004) }\end{array}$} \\
\hline & \multicolumn{4}{|c|}{ Ho District } & \multicolumn{4}{|c|}{ AES District } \\
\hline & 2001 & 2002 & 2003 & 2004 & 2001 & 2002 & 2003 & 2004 \\
\hline $\begin{array}{l}\text { RH service utilization as a } \\
\text { proportion of in \& } \\
\text { outpatient }\end{array}$ & $40 \%$ & $50 \%$ & $60 \%$ & $64 \%$ & $41 \%$ & $50 \%$ & $53 \%$ & $60 \%$ \\
\hline $\begin{array}{l}\text { Total of number of trainings } \\
\text { per district/year }\end{array}$ & 7 & 5 & 12 & 10 & 3 & 2 & 2 & 8 \\
\hline $\begin{array}{l}\text { Proportion of RH training } \\
\text { per district/year }\end{array}$ & $\begin{array}{c}2 \\
(29 \%)\end{array}$ & $\begin{array}{c}3 \\
(60 \%)\end{array}$ & $\begin{array}{c}6 \\
(50 \%)\end{array}$ & $\begin{array}{c}3 \\
(30 \%)\end{array}$ & $\begin{array}{c}2 \\
(75 \%)\end{array}$ & $\begin{array}{l}0 \\
-\end{array}$ & $\begin{array}{c}1 \\
50 \%\end{array}$ & $\begin{array}{c}8 \\
100 \%\end{array}$ \\
\hline $\begin{array}{l}\text { Total number of health staff } \\
\text { trained }\end{array}$ & 122 & 91 & 313 & 60 & 85 & 25 & 55 & 280 \\
\hline $\begin{array}{l}\text { Proportion of RH staff } \\
\text { benefiting from training }\end{array}$ & $\begin{array}{c}25 \\
(20 \%)\end{array}$ & $\begin{array}{c}62 \\
(68 \%)\end{array}$ & $\begin{array}{c}36 \\
(12 \%)\end{array}$ & $\begin{array}{c}28 \\
(47 \%)\end{array}$ & $\begin{array}{c}60 \\
(70 \%)\end{array}$ & - & $\begin{array}{c}32 \\
(38 \%)\end{array}$ & $\begin{array}{c}136 \\
(49 \%)\end{array}$ \\
\hline
\end{tabular}

Similarly, the majority of the in-service training programmes on RH targeted RH staff. This implies that a substantial proportion of the time of service providers and, by extension, recurrent component of the health budget at the district level is spent on reproductive health services/activities. In the two study districts, district directors have the authority to mobilize funds outside the regular budget for RH activities. However, this is neither structured nor has the district got the skills to do so. For example, 5 percent of the District Assembly Common Fund (DACF) has been earmarked for the health sector, representing an additional source of funding for health. District Health Management Teams must apply for this on a competitive basis with other sector ministries. None of the two districts have been able to access the DACF. There was the view among district directors that the DA does not see health as a priority. A district director's comment was:

"For health to become a priority it has to have a political flavor".

There was also another view that success in receiving an allocation depends on individual lobbying ability of the district director: Members of the DA social services 
subcommittee on health, however, expressed dissatisfaction with the DHMT in not doing enough lobbying work:

"Interaction and early awareness creation is important, since the DHMT set their priorities first, they should rope them into ours and get us convinced that this is very important. We want them to lobby. All sectors need to lobby for the DACF, if the health man will not come and tell us there is a looming epidemic we will not see it as a priority. Currently the health sector does not involve us much and does not lobby us much."

District directors in the two districts were not able to mobilize funds outside the regular budget and they claimed it was not easy accessing these funds. However, other districts not included in this study were reported to have accessed these funds. Clearly, there is room for accessing local funds so regional and district managers should explore all options.

\subsubsection{What is the capacity of districts to deliver RH services?}

The study assessed existing capacity of health facilities to deliver $\mathrm{RH}$ services. A scale was used, where the mean score of each service was compared against a minimum and maximum score. The scale includes four major capacity measures; supplies/drugs, equipment, protocols and guidelines. These capacity measures were assessed for each RH component. An overall score of 118 was derived after aggregating the individual score for each item in the facility assessment questionnaire (Annex 1).

\begin{tabular}{|c|c|c|}
\hline \multicolumn{3}{|c|}{$\begin{array}{c}\text { Table 6: Facility Capacity to Deliver } \\
\text { Reproductive Health Services }\end{array}$} \\
\hline RH services & $\begin{array}{l}\mathrm{Ho} \\
\mathrm{N}=41\end{array}$ & $\begin{array}{l}\text { AES } \\
\mathrm{N}=24\end{array}$ \\
\hline \multicolumn{3}{|l|}{ ANC } \\
\hline Drugs (Score 0-5) & 2.49 & 3.29 \\
\hline Equipment (score 0-11) & 5.98 & 8.83 \\
\hline Protocols (Score 0-5) & 0.88 & 1.21 \\
\hline Lab supplies (Score 0-7) & 1.27 & 3.08 \\
\hline Max. score ANC(28) & 10.62 & 16.41 \\
\hline \multicolumn{3}{|l|}{ STI } \\
\hline Drugs (Score 0-7) & 1.36 & 1.40 \\
\hline Protocols (Score 0-7) & 3.56 & 2.50 \\
\hline Lab supplies (Score 0-6) & 0.60 & 0 \\
\hline Max. score STI (20) & 5.52 & 3.90 \\
\hline \multicolumn{3}{|l|}{ HIV } \\
\hline Drugs (ART) (Score 0-4) & 0.00 & 0.04 \\
\hline Protocols (Score $0-5)$ & 0.56 & 0.75 \\
\hline Lab. supplies (Score 0-6) & 0.07 & 0.38 \\
\hline Max Score HIV (15) & 0.63 & 1.17 \\
\hline \multicolumn{3}{|l|}{ FP } \\
\hline $\begin{array}{l}\text { Commodities } \\
(\text { Score } 0-10)\end{array}$ & 5.88 & 4.33 \\
\hline $\begin{array}{l}\text { IEC materials } \\
(\text { Score } 0-6)\end{array}$ & 4.15 & 2.83 \\
\hline Equipment (Score 0-4) & 2.71 & 3.75 \\
\hline Max. score FP (20) & 12.74 & 10.91 \\
\hline \multicolumn{3}{|l|}{ Delivery } \\
\hline $\begin{array}{l}\text { Supplies \& drugs } \\
\text { (Score 0-19) }\end{array}$ & 8.71 & 15.96 \\
\hline Baby supplies (0-6) & 1.93 & 2.54 \\
\hline $\begin{array}{l}\text { Assisted Delivery } \\
\text { Supplies (Score 0-8) }\end{array}$ & 0.56 & 0.75 \\
\hline $\begin{array}{l}\text { Delivery protocols } \\
\text { (Score 0-2) }\end{array}$ & 0.3 & 0.75 \\
\hline Max. score Delivery(35) & 11.5 & 20 \\
\hline Total Score (0- 118) & 41.01 & 52.39 \\
\hline
\end{tabular}


Our findings (Table 6) show that capacity is very limited even though the majority of facilities reported to offer a range of RH services. The total mean score for Ho and AES was 41.01 and 52.39 respectively.

Extremely weak capacity was found in the area of HIV/AIDS. None of the three hospitals in both study districts had Anti-Retroviral Therapy (ART). Only one private clinic provided ART. Availability of STI drugs was also found to be limited. Similarly, availability of laboratory supplies was extremely limited. The score for laboratory supplies for STI tests was close to zero out of a maximum score of seven. The score for supplies for HIV testing was equally bad for both districts ( 0.07 and 0.38 ; the maximum score was 6). The availability of protocols and guidelines was also found to be extremely low for all RH components. Capacity for cancers and infertility was not assessed since these services were generally not available.

\subsection{Discussion and Conclusion}

This study sought to answer three key questions:

- Is RH a priority at the district level?

- Is there a harmony or discrepancy between national and district level RH priorities?

- Does HSR facilitate or constrain priority setting for RH at the district level?

The study confirms that reproductive health is a "stated" priority at both the national and district levels. Priority setting is essentially driven at the national level. The study suggests that the national level sets priorities and districts implement them. The sector priorities are determined at the health summits by key partners signing the aide mémoire. Evidence on reproductive health issues is discussed during the summits but the decisions on priorities are negotiated during the business meetings and by partners signing the aide mémoire.

Health sector reforms in Ghana tend to support and reinforce a focus on the RH package at the district level in three ways. First, the organization of services in health institutions makes the provision of $\mathrm{RH}$ almost mandatory since all health institutions at the district have RH/FP units that are responsible for safe motherhood and family planning services. This institutional arrangement ensures that reproductive health services stand out as a separate entity even in the integrated approach to health services in the country.

Second, the sector-wide approach adopted key RH indicators that form the basis for assessing sector-wide performance and ensuring accountability at the district level. For that reason the discourse at the sector level covers both RH service delivery and systems development. It is assumed under these circumstances that HSR in Ghana should lead to the delivery of RH interventions. However, our findings suggest that 
HSR are not translating into service delivery because of inadequate capacity in terms of drugs, supplies, equipment and service protocols.

Third, financing reforms did not discriminate in favor of RH services; nevertheless since the late nineties the country has been introducing exemptions that have increasingly focused on ANC and supervised delivery. This is to be reinforced under the NHIS programme.

Ghana is, however, currently facing the challenge of harmonizing a comprehensive definition of RH and the reality of selective implementation at the district level. There is therefore a gap between the RH components as stated in the national policy and the components available at the district level.

The reality districts face is that they do not have enough capacity to do all that has been defined in the national policy and therefore have to make choices within the institutional arrangements defined in the health sector. The findings suggest that the process for selecting priorities at the district level is embedded in the managerial process at the district level and is essentially negotiated and dependent on the interests of district directors of health services and their teams, with very little involvement of other actors outside the GHS.

Furthermore, providers at the district level tend to focus on aspects of RH consistent with their mission and comparative advantage. Both the public and private health institutions tend to focus on safe motherhood; FP and STI/HIV AIDS while NGOs tend to focus on the abandonment of harmful traditional practices and promotion of sexual health. The management of infertility and $\mathrm{RH}$ cancers is absent in both districts.

The fact that national level priorities are district level priorities leads us to conclude that the thrust of activities at the district level is about building capacity to implement national priorities rather than selecting priorities. Secondly, the challenge facing $\mathrm{RH}$ is not HSR per se but the broad range of RH services and the capacity required to ensure that they are fully integrated into the health system. The contribution of health sector reforms to reproductive health is in ensuring that health systems development under HSR keeps pace with the capacity needed to deliver RH interventions. In the case of Ghana, it appears HSR has so far been unable to do so.

Recommendations for bridging the policy implementation gap include:

- Ensuring that RH advocates participate in national policy dialogue. This will ensure that the policy dialogue gives balanced attention to issues of systems development and reproductive health service delivery and indeed ensure that health sector reforms deliver health interventions.

- Investing in strengthening systems for procurement and distribution of drugs and other supplies required for the integrated delivery of RH services. This is 
particularly important because inadequate inputs, including equipment and supplies, at the points of service delivery is one of the key constraints to the delivery of health services and has emerged as the major gap between the rhetoric of health sector reforms and the reality of service delivery.

- Recognizing that the public sector alone cannot deliver the comprehensive RH package defined in the national RH policy and that other implementers, in particular NGOs, have a comparative advantage in the delivery of certain components. NGOs should, therefore, be mobilized and funded to deliver these packages to ensure availability of a comprehensive package of RH services at the district level.

- Districts could mobilize more funds from District Assemblies to support implementation of RH activities. This will, however, require increased participation of other critical actors such as the District Assembly and District Health Committee in the dialogue on health policies and programmes at the district level. 


\section{References}

Addai E and L. Gaere (2001) Capacity-building and systems development for Sector-Wide Approaches (SWAps): the experience of the Ghana health sector. A report of one of three case studies commissioned by DFID Health Systems Resource Center, January 2001

Akosa, AB; Nyonator FK, Phillips, JF and TC Jones (unpublished) Health Sector Reforms, Field Experiments, and Systems Research for Evidence-Based Program Change and Development in Ghana. Paper prepared for the Rockefeller Foundation Bellagio Confernece Center Seminar: From Pilot Project to Policies and Programs. March 31 - April 5, 2003.

Bodadilla, JL. 1996. Priority Setting and Cost Effectiveness. In: Janovsky K. (ed.) Health Policy and Systems Development, An Agenda for Research, World Health Organization.

Enyimayew N. 2003 Role of UNFPA in SWAps: Study in Four Countries - Ghana Documentary Review. A Report submitted to UNFPA as part of the case study on role of UNFPA in SWAp in Ghana, September 2003

Ham, C. 1996 Priority Setting in Health. In: Janovsky K. (ed.) Health Policy and Systems Development. An Agenda for Research, World Health Organization: Geneva.

Hill PS, 2002 Between intent and achievement in sector-wide approaches: staking a claim for reproductive health. Reproductive Health Matters, Volume 10, Number 30, November 2002, 29 - 37.

Jeppsson, A. 2002 SWAp dynamic in a decentralized context: experiences from Uganda. Social Science and Medicine 55 (2002) 2053 - 2060.

Ghana Health Service (GHS) 2004 Review of the Year 2003 Programme of Work. Final Report, Ghana Health Services, July 20044: PPME-GHS

Ghana Health Service (GHS) 2003 Implementation of Government's Exemption Policy in the Ghana Health Services - Where do we go from here? An issues paper prepared for Ghana Health Service Council, July 2003.

Ghana Health Service (2002) Maternal Health/Death Audit Guidelines, Reproductive and Child Health Unit, Public Health Division, Ghana Health Service, 2002. 
Ghana Health Service (2003) HIV Sentinel Survey Report 2003. National AIDS/STI Control Programme, Ghana Health Service. March 2003.

Ghana Health Service (2003) National Reproductive Health Service Policy and Standards: Second Edition, December 2003.

Ghana Statistical Service (GSS), Noguchi Memorial Institute for Medical Research (NMIMR), and ORC Macro. 2004 Ghana Demographic and Health Survey 2003. Calverton, Maryland: GSS, NMIMR, and ORC Macro.

Mayhew S, Gerein N, and A. Green 2003 Sexual and reproductive health and health systems development: Inter-linkages and dialogue: An overview of Key issues. Paper prepared as a background for the International Conference on Sexual and Reproductive Health and Health Systems Development. 8 - 11 th September, Leeds, UK.

Mayhew S, Adjei S. 2004 Sexual and reproductive health: challenges for priority setting in Ghana's health reforms. Health Policy and Planning; 19(sppl.1): 49-60. Ministry of Health (MOH) 1998 Statement of Responsibilities, Government of Ghana.

Ministry of Health (MOH) 2002. The Second Health Sector 5 Year Programme of Work 2002-2006. Partnerships for Health: Bridging the Inequality Gap. Government of Ghana, January 2002.

Ministry of Health (MOH) 2004 The Ghana Health Sector Annual Programme of Work 2004. Ministry of Health, January 2004.

Standing H, 2002. An overview of changing agendas in the health sector reforms. Reproductive Health Matters, Volume 10 Number 30, November 2002, 19-28.

UNFPA/MOH March 2004 Ghana Health Sector Five Year Programme of Work (2002-2006): An in-depth review of the health sector response to maternal mortality in Ghana by 2003.

Walt G, Gilson, L. 1994 reforming the health sector in developing countries: The central role of the policy analysis. Health Policy and Planning 9: 353-370.

Reichenbach, L. The Politics of Priority Setting for Reproductive Health: Breast Cancer and Cervical Cancer in Ghana. Reproductive Health Matters, Volume 10 Number 30, November 2002, 47 - 57. 


\begin{tabular}{|c|c|}
\hline \multicolumn{2}{|r|}{ Reproductive Health Capacity Measures } \\
\hline \multirow[t]{10}{*}{1} & Protocols for STI \\
\hline & a) Confidentiality protocol or policy for STI \\
\hline & b) Informed consent protocol for STI testing \\
\hline & c) National Reproductive Health Service Protocols \\
\hline & d) Clinical guidelines for diagnosing and treating STI \\
\hline & $\begin{array}{l}\text { e) Guidelines for using syndromic approach for diagnosing and } \\
\text { treating STIs }\end{array}$ \\
\hline & f) Guidelines for diagnosing HIV/AIDS \\
\hline & g) Guidelines for PMCT \\
\hline & $\begin{array}{l}\text { h) Clinical guidelines for treating HIV/AIDS (Anti-retroviral use } \\
\text { and opportunistic infections) }\end{array}$ \\
\hline & i) Self Directed Learning (SDL) models for STI/HIVAIDS \\
\hline \multirow[t]{6}{*}{2} & STI Job aid \\
\hline & a) Visual aids for teaching HIV/AIDS \\
\hline & b) Flip chart for STI/HIV \\
\hline & c) Audio-visual for teaching about STI and HIV/AIDS \\
\hline & d) Model for demonstrating use of condom \\
\hline & e) Stop AIDS Love life poster \\
\hline \multirow[t]{4}{*}{3} & Booklet/pamphlet for clients to take home \\
\hline & a) On STI \\
\hline & b) HIV questions \& answers booklet \\
\hline & c) Other pamphlet on HIV/AIDS \\
\hline \multirow[t]{6}{*}{4} & HIV/AIDS Protocols and Guidelines \\
\hline & a) Guidelines for Prevention of Mother to Child Transmission \\
\hline & b) Guidelines for diagnosing HIV/AIDS \\
\hline & $\begin{array}{l}\text { c) Guidelines for treating HIV/AIDS? (Anti-retroviral use } \\
\text { and/or opportunistic infections) }\end{array}$ \\
\hline & d) Confidentiality protocol for HIV/ AIDS clients \\
\hline & e) Informed consent protocol for HIV/AIDS \\
\hline \multirow[t]{4}{*}{5} & Items required for laboratory examination \\
\hline & a) Microscope \\
\hline & b) Centrifuge \\
\hline & c) Slides and covers (malaria smears; gram stain) \\
\hline \multirow[t]{7}{*}{6} & Supplies for HIV/AIDS tests \\
\hline & a) Rapid test \\
\hline & b) ELISA + SCANNER \\
\hline & c) Western Blott \\
\hline & d) HIV SPOT test \\
\hline & e) CD 4 \\
\hline & f) HIV viral load \\
\hline \multirow[t]{5}{*}{7} & Supplies for STIs tests \\
\hline & a) VDRL \\
\hline & b) Carbon antigen \\
\hline & c) Chocolate Agar (culture media) \\
\hline & d) Crystal violet \\
\hline
\end{tabular}




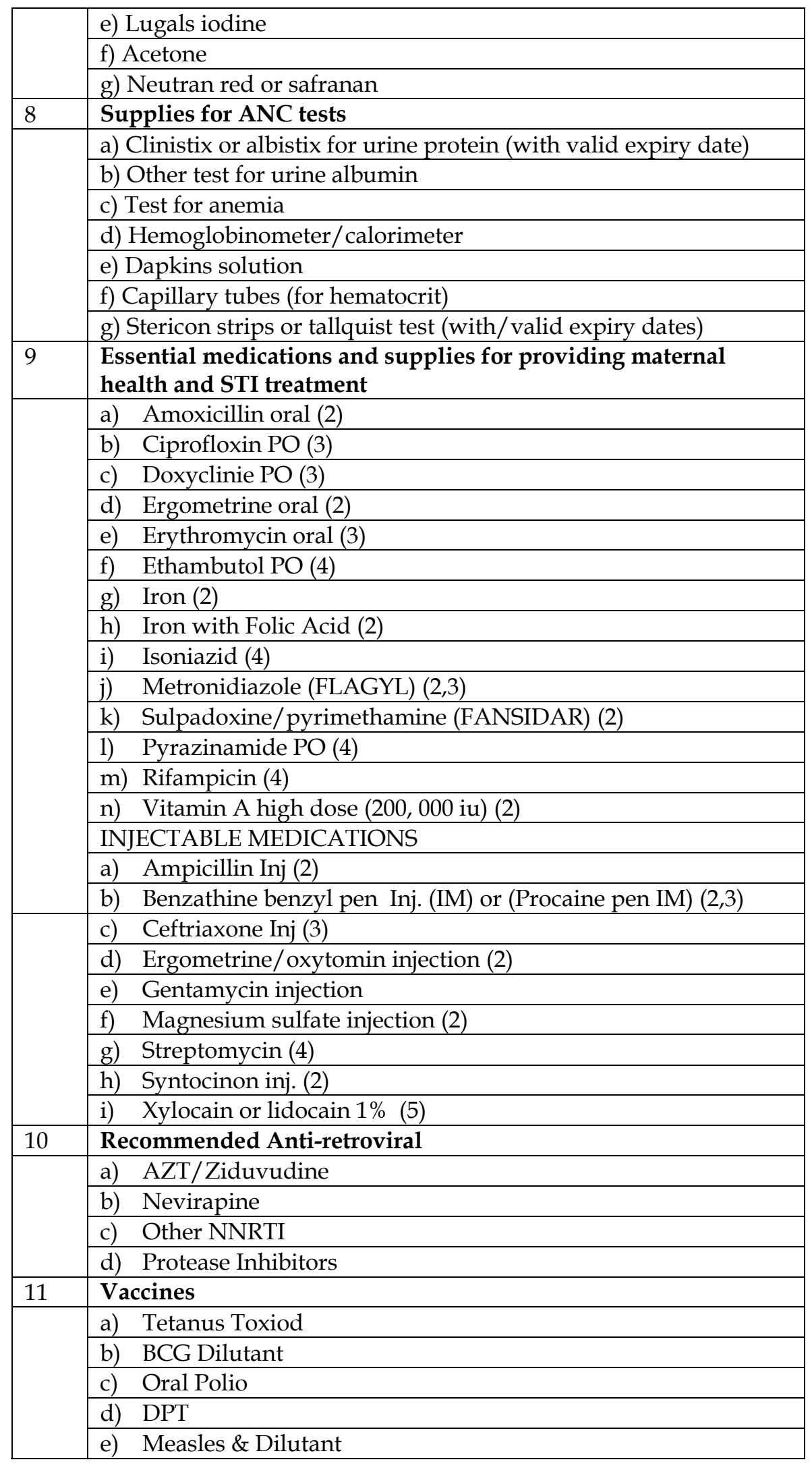




\begin{tabular}{|c|c|}
\hline 12 & Family planning contraceptive supplies \\
\hline & a) Oral pill with progesterone \\
\hline & b) Oral pill (combined) \\
\hline & c) Injectable (monthly) \\
\hline & d) Injectable (2/3 monthly) \\
\hline & e) Norplant \\
\hline & f) Condom (male) \\
\hline & g) Condom (female) \\
\hline & h) Intrauterine device (IUD) \\
\hline & i) Vaginal form tablets \\
\hline & j) Emergency contraceptive \\
\hline \multirow[t]{7}{*}{13} & Family Planning visual aid for teaching \\
\hline & a) Different family planning methods \\
\hline & b) Models for demonstrating use of condom \\
\hline & c) Posters on family planning \\
\hline & d) Essentials of Contraceptive Technology" poster \\
\hline & $\begin{array}{l}\text { e) Information booklet/pamphlet on family planning for clients } \\
\text { to take home }\end{array}$ \\
\hline & $\begin{array}{l}\text { f) The Essentials of Contraceptive Technology book } \\
\text { (HATCHER) }\end{array}$ \\
\hline \multirow[t]{5}{*}{14} & Items for family planning services \\
\hline & a) Blood pressure gauge \\
\hline & b) Stethoscope \\
\hline & c) Weighing scale \\
\hline & d) Syringes and needles \\
\hline \multirow[t]{12}{*}{15} & Essential equipment for antenatal care services \\
\hline & a) Blood pressure gauge \\
\hline & b) Stethoscope \\
\hline & c) Fetal stethoscope \\
\hline & d) Thermometer \\
\hline & e) Infant scale \\
\hline & f) Adult scale \\
\hline & g) Measuring tape \\
\hline & h) Vaginal speculum (L) \\
\hline & i) Vaginal speculum $(\mathrm{M})$ \\
\hline & j) Vaginal speculum (S) \\
\hline & k) Examination couch/table/bed \\
\hline \multirow[t]{6}{*}{16} & Antenatal care protocols and teaching materials \\
\hline & a) National Reproductive Health Policy and Standards \\
\hline & b) Standard Guidelines/protocol for Focused Antenatal Care \\
\hline & c) Revised Maternal Cards \\
\hline & $\begin{array}{l}\text { d) Guidelines for Prevention of Mother to Child HIV/AIDS } \\
\text { Transmission (PMCT) }\end{array}$ \\
\hline & e) Focused ANC Job aid \\
\hline \multirow[t]{5}{*}{17} & Items for delivery care \\
\hline & a) Soap \\
\hline & b) Scissor/blade \\
\hline & c) Clamp/umbilical tie \\
\hline & d) Ergometrine oral \\
\hline
\end{tabular}




\begin{tabular}{|c|c|}
\hline & e) Ergometrine Inj. With syringe and needle \\
\hline & $\begin{array}{l}\text { f) Spotlight source (flashlight or examination light accepted) } \\
\text { Lantern NOT Acceptable }\end{array}$ \\
\hline & g) Table and stool for delivery \\
\hline & h) Hand-washing items (soap and towel) \\
\hline & i) Single use towel \\
\hline & j) Water for hand-washing \\
\hline & k) Clean gloves \\
\hline & 1) Sharps container \\
\hline & m) Decontamination solution for clinical equipment \\
\hline & n) Skin antiseptic (e.g chlorhexidine, savlon, detol) \\
\hline & o) IV infusion set \\
\hline & p) Intravenous: ethier Ringers lactate, D5NS, or NS infusion \\
\hline & q) Injectable Ergometrine \\
\hline & r) Syringes and needles \\
\hline & s) Suture material with needle \\
\hline & t) Sterile scissors/blade \\
\hline & u) Needle holder \\
\hline 18 & Supplies for baby \\
\hline & a) Bag and mask or tube and mask (baby) for resuscitation \\
\hline & b) Resuscitation table for baby \\
\hline & c) Heat source \\
\hline & d) Baby scale \\
\hline & e) Mucous extractor/suction machine \\
\hline & f) Cord ties/cordclamps \\
\hline & g) Delivery protocols \\
\hline & h) Reference guidelines for delivery and emergency care \\
\hline & i) Blank partographs \\
\hline 19 & Items for assisted delivery \\
\hline & a) Forceps \\
\hline & b) Vacuum extractor \\
\hline & c) Does this facility have a Manual vacuum aspirator \\
\hline
\end{tabular}

